\title{
O TRABALHO COMO PRINCIPIO EDUCATIVO E COMO PRINCIPIO DE ALIENAÇÃO: POSSIBILIDADES E LIMITES DA PEDAGOGIA DA ALTERNÂNCIA
}

\author{
Ricardo Palaro ${ }^{1}$ \\ Maria de Lourdes Bernartt ${ }^{2}$ \\ Universidade Tecnológica Federal do Paraná (UTFPR)
}

\section{RESUMO}

A temática tratada nesse artigo faz parte de uma pesquisa mais ampla desenvolvida no Programa de Pós Graduação em Desenvolvimento Regional da UTFPR campus Pato Branco. O questionamento que se levanta é sobre a possibilidade de captar na Pedagogia da Alternância elementos da categoria trabalho bem como também elementos da categoria trabalho como princípio educativo. Para isso, este artigo apresenta reflexões sobre o trabalho como princípio educativo e principio de alienação, bem como discute esta relação na Pedagogia da Alternância. Os primeiros resultados mostram que a Pedagogia da Alternância está longe de ser vista como revolucionária.

Palavras-chave: trabalho, trabalho como princípio educativo, alienação, educação, Pedagogia da Alternância.

\section{Pedagogy of Alternation: the work as an educational principle and as a principle of sale: limits and possible}

\begin{abstract}
The issue addressed in this article is part of a broader research developed in the Graduate Program in Regional Development of the campus UTFPR Pato Branco. The question that arises is the possibility to capture elements of this pedagogical work category and also elements of the working class as an educational principle. The article presents reflections on the work as an educational principle and principle of alienation as well as discusses this relationship in the Pedagogy of Alternation. The first results show that the Pedagogy of Alternation is far from being seen as revolutionary.
\end{abstract}

Keywords: work, work as an educational principle, education, alienation, Pedagogy of Alternation.

\section{Introdução}

O presente estudo faz parte do Projeto de Pesquisa, que ainda está em construção, apresentado no Programa de Pós Graduação em Desenvolvimento Regional (PPGDR/UTFPR campus Pato Branco), cujo intuito é trazer à tona a discussão acerca da Pedagogia da Alternância tentando entender a proposta de sua dinâmica e se esta pode ser compreendida como uma educação que vise o trabalho como princípio educativo ou como mera reprodução da educação capitalista.

O interesse por esse tema surgiu nos encontros, conversas e debates propiciados no âmbito do referido Programa, por professores que já vem há algum tempo pesquisando sobre a modalidade de ensino da Pedagogia da Alternância. A possibilidade de investigação sobre a categoria trabalho no contexto da Pedagogia da Alternância é 
oportuna nesse momento histórico devido ao grau de imersão e consolidação dessa proposta como instrumento de educação de jovens que moram no campo.

Neste artigo apresentam-se os conceitos de trabalho, trabalho como principio educativo, a proposta da Pedagogia da Alternância, como surgiu e se consolidou e como está sendo aplicada atualmente. Por fim, tenta-se delinear as possibilidades e limites que apareceram na nossa pesquisa, no que se refere à proposta educacional da Pedagogia da Alternância sob uma leitura pelo viés do trabalho como princípio educativo ou como principio de alienação.

\section{1- O trabalho e o trabalho como princípio educativo}

Ao começar investigar a categoria trabalho constata-se que com o conceito de educação está intimamente ligado. Por educação tem-se em mente o radical latino ducor que, por sua vez, deriva do termo Dux que significa general, comandante, guia. Logo, ser educado é estar sob o jugo de um guia, pois este conduz, comanda.

A reflexão sobre educação e trabalho é uma preocupação constante nos discursos educacionais, sendo uma questão justa e legítima e pertinente. Apesar disso, esta discussão tem sido, por vezes, apresentada de forma descontextualizada, ora superestimando a importância do trabalho em detrimento da educação, ora o inverso.

No Brasil, vários autores tem se dedicado na discussão acerca do trabalho e da educação. Um dos mais notáveis é Dermeval Saviani, que apresenta uma leitura dos textos de Marx de forma contextualizada e por isso atual. Ao analisar o capitalismo, Saviani (2002, p. 23) apresenta que a tendência predominante do capitalismo, em seu primeiro estágio, "procurou converter as primeiras unidades de produção que eram autônomas, artesanais, em trabalho assalariado. Esta face do capitalismo criou uma divisão do trabalho, tornando-o coletivo e diminuindo o tempo de produção da fábrica comparada ao período que levava o artesão independente em sua produção".

A sofisticação da ciência e da tecnologia introduziu a maquinaria no ambiente fabril, "reforçando a racionalização da produção e as especializações, cada funcionário era muito qualificado para a sua tarefa, sem saber do processo todo" (SAVIANI, 2002, p. 23). Esta fragmentação do trabalho em operações simples trouxe mudanças significativas no sentido em que, os procedimentos podendo agora ser efetuado por máquinas, poderiam ser controlados por qualquer funcionário, e sendo assim, as habilidades manuais ficam relegadas.

O reflexo deste modelo capitalista é a "desqualificação do trabalhador, na medida em que este não precisa mais deter o conhecimento do processo de produção como um todo, apenas a sua parte (SAVIANI, 2002, p. 23). A sofisticação da ciência, ao contrário, não implicou diretamente em qualificação da massa de trabalho, mas na superqualificação de poucos que detinham o conhecimento dos processos produtivos como um todo. Essa divisão do trabalho "não socializa o processo da produção de um produto - nem da técnica nem do trabalho intelectual - impedindo os trabalhadores que se apoderem das etapas produtivas" (SAVIANI, 2002, p. 23). Isso só contribuiu ainda mais para a centralização do poder.

Estas relações de poder aconteceram em diferentes dimensões: "no rígido controle sobre a produção, no rígido controle sobre o trabalhador e ainda, sobre a cobrança incessante do aumento da produtividade" (SAVIANI, 2002, p. 23). E para o desempenho do trabalho na fábrica era necessário certo preparo para função que o trabalhador exerceria na sua lida diária. Em outras palavras, o ensino estava atrelado à vida na fábrica. Mas afinal, que tipo de ensino? 
Para tentar entender essa dinâmica far-se-á uma reflexão acerca da educação sob o viés histórico. E analisando os primórdios da existência humana percebe-se que a educação praticamente coincide com a mesma. Em outros termos,

as origens da educação se confundem com as origens do próprio homem. A medida em que determinado ser natural se destaca da natureza e é obrigado, para existir, a produzir sua própria vida é que ele se constitui propriamente enquanto homem. Em outros termos, diferentemente dos animais, que se adaptam à natureza, os homens têm que fazer o contrário: eles adaptam a natureza a si. O ato de agir sobre a natureza, adaptando-a às necessidades humanas, é o que conhecemos pelo nome de trabalho. Por isto podemos dizer que o trabalho define a essência humana. Portanto, o homem, para continuar existindo, precisa estar continuamente produzindo sua própria existência através do trabalho. Isto faz com que a vida do homem seja determinada pelo modo como ele produz sua existência (SAVIANI, 1998, p. 03).

Nessa discussão o entendimento do conceito de trabalho atrelado ao conceito de educação requer que se pense o primeiro como principio do segundo, ou seja, que se pense o trabalho como principio educativo.

Ainda em Saviani, encontra-se uma possível síntese sobre essa temática, pois segundo este autor, todo sistema educacional se estrutura a partir da questão do trabalho,

pois o trabalho é a base da existência humana, e os homens se caracterizam como tais na medida em que produzem sua própria existência, a partir de suas necessidades. Trabalhar é agir sobre a natureza, agir sobre a realidade, transformando-a em função dos objetivos, das necessidades humanas. A sociedade se estrutura em função da maneira pela qual se organiza o processo de produção da existência humana, o processo de trabalho (SAVIANI, 1986, p. 14).

Outros pensadores que estudam a categoria trabalho baseiam-se em Marx, para fundamentar seus argumentos. E é nesse pensador que se encontra uma definição do trabalho: "trabalho é um processo entre o homem e a Natureza, um processo em que o homem, por sua própria ação, media, regula e controla seu metabolismo com a Natureza" (MARX, 1983, p. 149).

Nessa linha de raciocínio, encontramos Tumolo que aponta que se é verdade que o trabalho é a base da existência humana, então "seria necessário indagar como é produzida essa existência humana, por intermédio do trabalho, na especificidade do modo capitalista de produção". Algumas das questões seriam: "Qual é, nesta forma social determinada, o significado do trabalho? Em que medida seria possível considerar o trabalho como princípio balizador de uma proposta emancipadora de educação no interior do capitalismo?" (TUMOLO, 2005, p. 241).

Para Soares \& Trindade, o trabalho como princípio educativo é norteador dos processos de humanização e de atualização histórica do próprio homem, "por ser práxis que comporta como um de seus fundamentos, a integração entre ciência, cultura e trabalho, mas ao mesmo tempo, o trabalho na formação histórica do capitalismo impõe limites à emancipação humana" (2007, p. 05).

A categoria princípio educativo do trabalho, compreendida dentro do capitalismo, determinada pelas bases materiais de produção, remete a se pensar na sua dupla face: 
a primeira contribui para a educação do trabalhador, onde desta forma ele possa reconhecer-se no produto de sua obra, aprendendo a se organizar, reivindicar seus direitos, desmistificar ideologias, dominar conteúdos do trabalho, compreender as relações sociais e a função que nela desempenham; a segunda, o trabalho na formação social do capitalismo, ao se instituir como alienação, reforça o sentido da adaptação e impõe limites a emancipação humana (SOARES \& TRINDADE, 2007. 06)

Outro pensador que se destaca nessa discussão é Frigotto. Para ele, "o trabalho é parte fundamental da ontologia do ser social" (2005, p. 02). A aquisição da consciência se dá pelo trabalho, pela ação sobre a natureza. O trabalho, neste sentido, "não é emprego, não é apenas uma forma histórica do trabalho em sociedade, ele é a atividade fundamental pela qual o ser humano se humaniza, se cria, se expande em conhecimento, se aperfeiçoa. O trabalho é a base estruturante de um novo tipo de ser, de uma nova concepção de história" (FRIGOTTO, 2005, p. 02).

$\mathrm{O}$ trabalho nada mais do que a consciência moldada por esse agir

prático, teórico, poético ou político que vai impulsionar o ser humano em sua luta para modificar a natureza (ou para dominá-la, como se dizia no passado, antes que se tomasse consciência da destruição que o homem vem operando sobre o planeta) (FRIGOTTO, 2005, p. 03).

E por consciência entende-se que seja a capacidade de representar o ser de modo ideal. Nas palavras de Frigotto: "consciência é a capacidade de colocar finalidades às ações, de transformar perguntas em necessidades e de dar respostas a essas necessidades" (2005, p. 04). Diferente dos animais que agem "guiados pelo instinto, de forma quase imediata, o ser humano age por meio de mediações, de recursos materiais e espirituais que ele implementa para alcançar os fins desejados" (FRIGOTTO, 2005, p. 04).

Frigotto parafraseando Marx diz que o homem é como um "ente-espécie não apenas no sentido de que ele faz da comunidade o seu objeto, mas no sentido de tratar a si mesmo como a espécie vivente, atual, como um ser universal e, conseqüentemente, livre. Sua base de vida física é a natureza - seu corpo inorgânico" (FRIGOTTO, 2005, p. 05).

$\mathrm{O}$ homem interage conscientemente com a natureza por ser seu meio direto de vida, fazendo-o pelo trabalho, instrumento material de sua atividade vital. Portanto, "a natureza fornece os meios materiais a que o trabalho pode aplicar-se e também os meios de subsistência física do trabalhador" (FRIGOTTO, 2005, p. 05). Porém, a intervenção do homem sobre a natureza, por meio de seu trabalho, implica torná-la não mais o meio externo para a existência do trabalho, pois o próprio produto do trabalho passa a ser esse meio material.

Frigotto é incisivo em afirmar que o trabalho como princípio educativo não é apenas "uma técnica didática ou metodológica no processo de aprendizagem, mas um princípio ético-político" (FRIGOTTO, 2005, p. 08). Dentro desta perspectiva, "o trabalho é, ao mesmo tempo, um dever e um direito" (FRIGOTTO, 2005, p. 08). Para o nosso autor em questão, o que é inaceitável e deve ser combatido são "as relações sociais de exploração e alienação do trabalho em qualquer circunstância e idade" (FRIGOTTO, 2005, p. 08).

Outra versão sobre o trabalho como princípio educativo é dada por Maria Franco. Segundo ela, pode-se atribuir dois sentidos ao conceito de trabalho. Por um lado, 
o trabalho pode ser concebido como a forma de ação originaria e especificamente humana através da qual o homem age sobre a natureza, transforma a ordem natural em ordem social, cria e desenvolve a estrutura e as funções de seu psiquismo, relacionando-se com outras pessoas, pensa, comunica-se, descobre, enfim, produz sua própria consciência e todo um conjunto de saberes que lhes possibilitarão viver em sociedade, transformar-se e transformá-la (FRANCO, 1989, p. 33).

Por outro lado, trabalho é "o exercício de uma função produtiva a favor da acumulação do capital" (FRANCO, 1989, p. 33). Nessa perspectiva, a principal categoria de análise do trabalho desloca-se de sua vinculação com a atividade humana e com o processo de humanização e recai na análise que ele assume sob as relações capitalistas de produção. A produção capitalista "exige intercâmbio de relações, mercadorias e dinheiro, mas sua diferença específica é a compra e venda de força de trabalho" (FRANCO, 1989, p. 33). O que o trabalhador vende e o que o capitalista compra "não é uma quantidade contratada de trabalho, mas a força de trabalho contratada por um período de tempo (FRANCO, 1989, p. 33).

Segundo a autora $(1989$, p. 33), desse ponto de vista torna-se temerário encarar o trabalho como principio educativo, pois o "processo de trabalho é dominado e modelado pela acumulação e expansão do capital e para a criação de um lucro". A essa finalidade todas as demais estão subordinadas, afetando, inclusive, as relações sócias mais amplas.

A única possibilidade de encarar o trabalho como principio educativo é "associando-o à concepção de atividade laboral vista como uma prioridade inalienável do individuo humano" (FRANCO, 1989, p. 33).

Para findar essa exposição apresenta-se como Gramsci apresenta o trabalho:

O conceito e o fato do trabalho (da atividade teórico-prática) é o princípio educativo imanente à escola elementar, já que a ordem social e estatal (direitos e deveres) é introduzida e identificada na ordem natural do trabalho. O conceito do equilíbrio entre ordem social e ordem natural sobre o fundamento do trabalho, da atividade teórico-prática do homem, cria os primeiros elementos de uma intuição do mundo liberta de toda a magia ou bruxaria, e fornece o ponto de partida para o posterior desenvolvimento de uma concepção histórico-dialética do mundo, para a compreensão do movimento do devenir, para a valorização da soma de esforços e de sacrifícios que o presente custou ao passado e que o futuro custa ao presente, para a concepção da atualidade como síntese do passado, de todas as gerações passadas, que se projetam no futuro (GRAMSCI, 1979, p. 130-131).

Tendo levantado em linhas gerais como vem sendo interpretada a categoria trabalho, agora é lícito tentar compreender o conceito de alienação frente à compreensão de trabalho e de trabalho como princípio educativo.

\section{2 - Trabalho e alienação}

Com o surgimento do capitalismo é intensificada a procura de lucro e o confinamento do operário na fábrica, retirando dele a posse do produto. Mas não é apenas o produto que não lhe pertence mais. Ele próprio deixa de ser o centro de si mesmo. Não 
escolhe seu salário, não escolhe seu horário, nem o ritmo do trabalho, passa a ser comandado de fora, por forças estranhas a ele. Em consequiência disso, acontece a humanização da mercadoria que leva à desumanização do homem, à sua coisificação, à sua reitificacao, sendo ele próprio transformado em mercadoria. Isto é, sua força de trabalho tem um preço de mercado. A mercadoria passa a ter valor superior ao homem.

Portanto, a alienação (do Latim: alienare - tornar algo alheio a alguém) não é simplesmente teórica, mas se manifesta na vida real do homem, na maneira pela qual, a partir da divisão do trabalho, o produto do seu trabalho deixa de lhe pertencer.

Para fundamentar alguns pressupostos e fazer uma análise sobre a categoria trabalho buscou-se apoio nos marxistas. E uma das perspectivas que se levanta de antemão para se pensar o trabalho está relacionada a seu sentido ontológico.

Segundo Tumolo, Engels (2004), na sua obra "Sobre a transformação do macaco em homem", enfatiza

que o trabalho é a condição básica de toda a vida humana; em suma, foi o trabalho que possibilitou o surgimento do homem. Em que pese todo o limite antropológico desta obra (escrita em 1876), o raciocínio desenvolvido é bastante ilustrador e toda a diferença entre o homem e os outros animais encontra-se no trabalho (TUMOLO, 2008, p. 05).

Da mesma maneira, servindo-se do texto de Engels, Braverman (1987, p. 45) também defende "a idéia do trabalho como atividade especificamente pertencente à espécie humana". Nisso entende-se o trabalho como aquela atividade, realizada pelo homem, que altera o estado natural da natureza para melhor servir-se dela, satisfazendo, com isso, suas necessidades.

Além disso, "o trabalho figura antes em sua mente, para depois exteriorizar-se, podendo, inclusive, ser executado por outras mãos, que não aquelas que o planejou" (TUMOLO, 2008, p. 05). Ainda a respeito do sentido ontológico do trabalho, Lessa (2002, p. 65) também afirma "que o trabalho é a categoria fundante do mundo dos homens. Essa atividade humana que transforma a natureza e o próprio homem é decisiva". É ela que "promove o salto para além dos instintos e constrói a existência social do homem" (LESSA, 2002, p. 65). Embora a vida não se resuma ao trabalho, não há vida humana sem trabalho. Essa perspectiva de compreensão do trabalho "não tem que ver com o trabalho abstrato, alienado, produtor de mais-valia (LESSA, 2002, p. 65).

Nas chamadas obras de juventude, "sobretudo nos Manuscritos EconômicoFilosóficos ou Manuscritos de 1844 (MARX, 1974), Marx refere-se ao trabalho no modo capitalista de produção como trabalho alienado ou estranhado" (TUMOLO, 2008, p. 05).

A esse respeito, Tumolo (2006, p.150) entende que a discussão concernente ao trabalho feita por Marx nos Manuscritos "é uma primeira incursão de um estudo da concepção que o autor foi construindo a respeito dessa categoria em suas principais obras". Começando pela distinção entre as noções de alienação e de estranhamento, Tumolo (2006, p. 150) argumenta que o cerne da discussão nesses escritos "é a relação de mútua determinação, no seio do capitalismo, entre trabalho estranhado e propriedade privada".

$\mathrm{O}$ autor entende que o estranhamento "se manifesta na vida do trabalhador porque este se encontra expropriado de qualquer propriedade e, por isso, a relação estranhamentopropriedade privada pode ser compreendida pela relação entre estranhamento e expropriação" (TUMOLO, 2006, p. 151). No entanto, em suas obras posteriores, sobretudo em O Capital, Marx compreende, "diferentemente, que a relação capitalista 
ocorre entre dois proprietários - um, dos meios de produção e outro, da força de trabalho-, de tal forma que a exploração é resultado de uma relação entre iguais, na qual não houve expropriação" (TUMOLO, 2006, p. 151).

Dessa forma, continua o autor,

\begin{abstract}
se o entendimento apresentado anteriormente, segundo o qual o fenômeno do estranhamento e, por conseguinte, do trabalho estranhado, só pode se configurar quando existe um processo de expropriação, e considerando que a exploração capitalista pressupõe a negação da expropriação, então algumas indagações se impõem. Será que as categorias de estranhamento e de trabalho estranhado continuam a ter validade explicativa nas chamadas obras da maturidade de Marx, nas quais trata da exploração capitalista? É possível supor que houve, na evolução da produção teórica marxiana, a superação dessa categoria? (TUMOLO, 2006, p. 160).
\end{abstract}

Com tais indagações, a compreensão de trabalho em Marx nos Manuscritos e em outras obras de seu período de juventude, "representa um primeiro esboço em sua produção sobre esse tema, que recebeu um tratamento analítico mais denso e aprofundado nos escritos posteriores, principalmente em O Capital" (TUMOLO, 2006, p. 151).

Pois bem, de uma maneira geral, tentou-se apresentar como vem sendo interpretada a categoria trabalho pelos marxistas. A partir de agora tentar-se-á levantar as características da Pedagogia da Alternância como proposta de educação do campo frente à categoria trabalho e à categoria trabalho como princípio educativo, ou como princípio de alienação. A análise proposta se volta para a compreensão da proposta da Pedagogia da Alternância tentando entender se ela é revolucionária ou simpatizante dos moldes de produção capitalista.

\title{
2- A Pedagogia da Alternância e trabalho: alternativa para a educação do campo
}

A Pedagogia de Alternância é uma alternativa entre tantas outras que surgiu para a educação no campo, mais especificamente em Centros de Formação por Alternância (Casas Familiares Rurais), com o objetivo de promover uma educação, formação e profissionalização eficaz e concreta mais apropriada à realidade do campo, isto é, o agronegócio. Mas afinal, o que é a Pedagogia da Alternância? O que são as Casas Familiares Rurais (CFR)? O Movimento das Casas Familiares Rurais nasceu em 1935, a partir da iniciativa de três agricultores e de um padre de um pequeno vilarejo da França que, de um lado, "prestaram atenção na provocação de um adolescente de quatorze anos que rejeitava a escola na qual tinha sido matriculado e, de outro, estavam atentos a seu meio, que queriam promover e desenvolver" (GIMONET, 1999, p. 40).

Assim o ensino e a formação não estavam separados da realidade do momento, mas "estreitamente associados a ela e se inscreviam num movimento, numa dinâmica de conjunto" (GIMONET, 1999, p. 41). Desta forma, o ensino para os adolescentes "tinha um sentido e podia se transformar em aprendizagens" (GIMONET, 1999, p. 41).

Nesse sentido, as CFR são escolas da região, criadas e geradas pelas pessoas do lugar, para as pessoas do lugar. Criar uma CFR é então "para um grupo de pessoas, para os pais, para uma comunidade, oportunidade para assumir seus destinos e a educação de seus filhos" (GIMONET, 1999, p. 43).

A Pedagogia praticada baseia-se na a Alternância, o que significa: "Alternância de tempo e de local de formação, ou seja, de períodos em situação sócio-profissional e em situação escolar" (GIMONET, 1999, p. 44). Nesse contexto, a Alternância significa, 
sobretudo, "uma outra maneira de aprender, de se formar, associando teoria e prática, ação e reflexão, o empreender e o aprender dentro de um mesmo processo" (GIMONET, 1999, p. 45). A Alternância representa uma maneira de aprender pela vida, "partindo da própria vida cotidiana, dos momentos experienciais, colocando assim a experiência antes do conceito" (GIMONET, 1999, p. 45).

De acordo com Gimonet (2007, p. 15), a Pedagogia da Alternância está fundamentada em quatro pilares, dois pilares da ordem das finalidades que buscam a formação integral (projeto pessoal) e o desenvolvimento do meio (socioeconômico, humano, político, etc.). E dois pilares da ordem dos meios que buscam a associação (pais, famílias, profissionais) e a alternância.

Para Gimonet (1999, p. 45), a Pedagogia da Alternância, nas CFR, “dá a prioridade à experiência familiar, social, profissional, ao mesmo tempo como fonte de conhecimentos, ponto de partida e de chegada do processo de aprendizagem, e como caminho educativo".

A Alternância diversifica e multiplica os formadores que atuam com os jovens. Estes formadores são

os pais, os profissionais responsáveis do estágio, os intervenientes dos meios sócio-profissionais e, evidentemente, os formadores dos CEFFA's (Centros Familiares de Formação por Alternância). que chamamos de monitores. Cada um contribui com seu saber específico, sua experiência, na área de suas competências. Um tema de estudo recebe assim esclarecimentos diferentes e complementares, onde cada um tem seu valor e é reconhecido (GIMONET, 1999, p. 45).

A responsabilidade das famílias, a parceria com a família, é ao mesmo tempo fonte de formação e desenvolvimento do meio. "Existem parceiros insubstituíveis que se inscrevem no tempo e que fazem com que o CEFFA exista" (TANTON, 1999, p. 100). São eles: "pais, monitores, mestres de estágio que assumem a responsabilidade educativa e que garantem o bom funcionamento - a colocação em prática - da Pedagogia da Alternância" (TANTON, 1999, p. 100). A parceria é saber reconhecer que o outro "é complementar e que o resultado da soma dos atores pode servir ao projeto que foi coletivamente construído" (TANTON, 1999, p. 100).

A família é para o jovem um ponto de referência e um suporte essencial para soluções dos problemas de inserção na sociedade. Esta "inserção sócio-profissional é o resultado de um longo processo de maturação do jovem que se desenvolve durante os anos de Alternância entre o meio familiar e profissional, e o meio escolar" (TANTON, 1999, p. 101).

Para Tanton (1999, p. 101) pode-se contentar em constatar que

os jovens encontram, neste caso, mais facilmente um emprego, um lugar na sociedade profissional, mas devemos sobretudo constatar que a Alternância não faz somente adaptar o jovem ao emprego, mas ela o ajuda a tornar-se um ser ativo e participante. Os jovens em alternância estão em situação real, o que provoca e motiva a formação.

Estar em situação concreta de trabalho corresponde a uma "necessidade sentida por uma maioria de adolescentes que procuram exercitar-se, descobrir-se, afirmar-se" (TANTON, 1999, p. 101). Estes jovens procuram ao mesmo tempo "serem úteis e considerados, sem que por isso queiram reproduzir o que os adultos ditam. A Alternância permite aos jovens participar da vida dos adultos através de um trabalho real" (TANTON, 1999, p. 101). 
A ação da CFR participa do desenvolvimento do meio porque

ela é de início voltada para o futuro, preparando jovens cidadãos. Isto porque ela associa o conjunto dos parceiros de todas as gerações sem distinção de origem e nem de classe social para partilhar a responsabilidade da educação e da promoção dos jovens e dos adultos (TANTON, 1999, p. 101).

Para a implementação do dispositivo pedagógico (formação alternada) é preciso saber suas finalidades e princípios. Finalidades: "formação integral da pessoa, educação, orientação e inserção socioprofissional, contribuição para o desenvolvimento da região onde está inserido o CEFFA" (GIMONET, 2007, p. 28).

Há uma forte relação entre vida e escola, as relações de trabalho e a escola, a experiência é considerada como suporte de formação. "Ela se impõe para uma formação contínua na descontinuidade das atividades, fazer uma ligação entre os dois espaçostempos (escola e meio) (GIMONET, 2007, p. 29).

Na Pedagogia da Alternância encontra-se vários instrumentos pedagógicos, a saber; Plano de Estudo; Estágio; Colocação em Comum; Tutoria; Coletivos de Jovens; Visita à Família e Comunidade; Visita e Viagem de Estudo; Serão de Estudo; Colaboração Externa; Cadernos Didáticos; Fichas de Trabalho; Atividade de Retorno-experiências; Projeto do Jovem Empreendedor Rural; Avaliação semanal; Avaliação formativa e o chamado 'Caderno de Vida ou Caderno da Realidade', este permite aos filhos dos agricultores "observação e análise direta da prática agrícola e estabelecer um elo entre a experiência, da vida familiar, social e o período escolar" (GIMONET, 2007, p. 32).

Cada ciclo de formação (os ciclos são semestrais) contém temas de estudos, sobre a vida profissional e sobre a vida familiar. As pesquisas e estudos propostos devem apresentar aos alternantes utilidade e sentido, para que seja duradouro.

Portanto, três elementos devem ser considerados:

pertinência em relação as atividades (experiência, contexto de vida). Pertinência à evolução do jovem (interesses, capacidades de apreender o meio, abordar uma profissão). Pertinência em relação à cultura do meio, modos de pensar, linguagem, formas de expressão. "Não é o programa em base de noções que determina estas escolhas, mas, sim, a progressão dos adolescentes ou adultos. É nesta base que se constrói o Plano de Formação" (GIMONET, 2007, p. 34-35).

O Plano de Formação visa garantir a implementação organizada da alternância, estrutura o percurso formativo. "A formação alternada supõe dois programas de formação: o da vida e o da escola. O primeiro oferece conteúdos informais e experiências, e o segundo conteúdos formais e acadêmicos" (GIMONET, 2007, p. 70). O Plano de Formação tem o objetivo de reunir estas duas lógicas.

Quatro são as finalidades da Pedagogia da Alternância: "1) orientação; 2) adaptação ao emprego (suprir a inadequação entre formação e emprego); 3) qualificação profissional (construir uma identidade profissional duradoura); 4) formação geral (permitir o mesmo acesso ao prosseguimento dos estudos através do ensino tradicional)" (GIMONET, 2007, p. 119).

No caso dos CEFFA, a situação que põe em atividade o capital social é "o aumento de responsabilidade na formação e no desenvolvimento local por parte do grupo de famílias associadas" (MARIRRODRIGA, 2007, p. 177). 
A alternância articula processos de "formação (capital humano) e desenvolvimento local mediante a participação, o compromisso associativo e o trabalho em rede (capital social)" (MARIRRODRIGA, 2007, p. 181).

O perfil do egresso que pretendem os CEFFA é de um líder local que "viva dignamente de seu trabalho e em seu território, um jovem capaz de empreender projetos que contribuam ao seu desenvolvimento pessoal e familiar, para conseguir assim o progresso de toda a comunidade" (MARIRRODRIGA, 2007, p. 183).

\subsection{Os pilares da Pedagogia da Alternância}

As CFRs têm quatro pilares que as caracterizam e as "sustentam": as associações mantenedoras da CFR, a Pedagogia da Alternância, a formação integral do aluno e o desenvolvimento local sustentável.

O primeiro desses pilares é a constituição de uma associação responsável pela CFR nos diversos aspectos: "econômicos, jurídicos e gestão. As CFRs representam para as suas associações, não um fim em si mesmas, mas um meio para alcançar o desenvolvimento local e coletivo" (CALVÓ, 1999, p. 15). Ou seja, através das CFRs suas associações podem atuar em projetos e atividades que favoreçam o desenvolvimento local ao mesmo tempo em que se propõem a formar as futuras gerações que vão dar continuidade ao projeto. Esse primeiro pilar é condição necessária à formação e manutenção de uma CFR, "porque sua existência se vincula a uma organização local de base participava, em que a associação das famílias, as comunidades, as instituições locais, os profissionais do setor são os responsáveis pela gestão e pelo desenvolvimento local" (CALVÓ, 1999, p. 15). Essas associações "não devem se confundir com as tradicionais associações de pais e mestres, que, de modo geral, existem para dar apoio externo à escola na qual estudam seus filhos" (CALVÓ, 1999, p. 15).

Essas associações são a condição apriorística da existência da CFR. Ela deve consistir em uma "organização de base democrática e participativa, composta por pais e outros atores comunitários, que tenham como principal objetivo a promoção do desenvolvimento local" (CALVÓ, 1999, p. 15).

O segundo pilar que caracteriza e sustenta uma Escola Familiar Rural é a adoção de uma proposta pedagógica específica: a Pedagogia da Alternância. No sentido geral, alternância significa segundo Calvó, um "conjunto dos períodos formativos que se repartem entre o meio sócio profissional (seja na própria família ou na empresa) e a escola. Isto sempre dentro de uma interação educativa escola-meio" (1999, p. 17).

Daí a importância da Escola Familiar Rural como uma alternativa de escolarização desse público, uma vez que "possibilita ao aluno ter acesso à escola, ao mesmo tempo em que permite a ele permanecer junto à família, à sua cultura e às atividades produtivas" (SILVA, 2003, p. 23).

O terceiro pilar que dá sustentação a uma CFR e a caracteriza como tal é a "formação integral da pessoa, de modo a lhe permitir o desenvolvimento pleno da personalidade e a capacidade de construir seu projeto de vida" (CALVÓ, 1999, p. 17). Essa "formação integral da pessoa" diz respeito a tudo aquilo que pode enriquecer a sua constituição como indivíduo,

considerando todos os elementos que se referem ou interferem na aprendizagem, como a organização escolar, a formação dos profissionais que nela atuam a configuração social, as representações vigentes no meio, 
o projeto de vida de cada um, as condições socioeconômicas da família e da comunidade etc (CALVÓ, 1999, p. 17).

A formação do jovem pela alternância implica o seu envolvimento em atividades produtivas, "de maneira a relacionar suas ações com a reflexão sobre o porquê e o como das atividades desenvolvidas" (Silva, 2003, p. 24). Ou seja, essa formação busca a interação entre as atividades práticas e a reflexão teórica sobre elas. Nessa perspectiva educativa "o jovem deve ser o protagonista de sua própria formação" (Gimonet, 2007, p. 45). Ele deve analisar quais conteúdos são relevantes para seu desenvolvimento pessoal e social. A atenção personalizada é importante nesse processo de formação, "pois a tutoria, o diálogo para revisão do caderno da realidade, as visitas às famílias e às comunidades são alguns dos procedimentos didáticos utilizados para atingir o objetivo da formação integral do aluno (CALVÓ, 1999, p. 17).

Por último, o quarto pilar que caracteriza e sustenta uma Escola Familiar Rural é a sua preocupação com questões voltadas para o desenvolvimento local e sustentável. A busca constante das CFRs em promover o desenvolvimento nas comunidades locais é "uma das suas principais características, pois foi este desejo de desenvolvimento local que fez as experiências educativas pautadas na Pedagogia da Alternância surgirem na França e expandirem-se para outros países" (SOUZA, 2011, p. 07). O desenvolvimento do meio no qual está inserida uma CFR resulta da interação de diferentes atores (FORGEARD, 1999, p. 64). A interação desses atores é concretizada dentro de dimensões humanas, econômicas, sociais, culturais, ambientais, numa perspectiva global.

Sendo assim, a partir da interação dos sujeitos, quando eles têm interesses individuais em comum, são conduzidas ações de desenvolvimento de competências, de atitudes, de comportamentos para um bem estar econômico e social melhor para todos que vivem nesse meio (FORGEARD, 1999). Portanto, quando os atores de um determinado contexto compartilham interesses de desenvolvimento em comum, eles podem utilizar as CFRs como "espaço de socialização de suas idéias e como lugar de partida para as ações e concretização dessas idéias" (SOUZA, 2011, p. 07).

\subsection{O conceito trabalho e trabalho como princípio educativo na Pedagogia da Alternância}

A Pedagogia da Alternância tem por base o ser humano como um ideal abstrato,

constitui-se enquanto forma de sistematização de um projeto de educação para o jovem do campo a partir de quatro finalidades; orientação, adaptação ao emprego, qualificação profissional e formação geral; elegendo como meio para alcançar estas finalidades a alternância e a associação entre famílias, professores, monitores e instituição (TRINDADE, 2010, p. 81).

Começamos por aí, a perceber alguns indícios da lógica capitalista dentro da proposta da alternância.

Trindade nos apresenta a forma de organização da Pedagogia da Alternância como uma forma de "mascarar o problema do trabalho infantil, e ainda mais, adequando o ensino à exploração da força de trabalho" (TRINDADE, 2010, p. 81). E segue mostrando que a prática da Pedagogia da Alternância "reforça e induz a ideia de que é possível produzir a 
vida na sociedade capitalista, inclusive na pequena propriedade, bastando para isso ser um profissional, ou um 'capitalistinha"” (TRINDADE, 2010, p. 81).

Partindo da premissa que a abordagem do conceito trabalho (que perpassa nas CFR) seja um problema, vê-se que este deixa ou deixou de ser uma atividade que possibilita a construção/produção/realização da existência para o homem do campo, a partir do momento que ele entra na lógica do capital. Isto é, hipoteticamente, as Casas Familiares Rurais que, por sua vez, usam a Pedagogia da Alternância, estão a serviço dessa lógica. "Não há assim espaço para crítica das relações capitalistas de produção muito menos para discutir uma alternativa para além do capital”, ressalta Mészáros (2005, p.53).

Essa reflexão esta pautada em Antunes, quando ele reflete sobre o trabalho, colocando-o como

... protoforma da práxis social, como momento fundante, categoria originaria, onde os anexos entre causalidade e teleologia se desenvolvem de modo substancialmente novo: o trabalho, como categoria de mediação, permite o salto ontológico entre os seres anteriores e o ser que se torna social. É, como a linguagem e a sociabilidade, uma categoria que se opera no interior do ser; ao mesmo tempo em que transforma a relação metabólica entre homem e natureza e, num patamar superior, entre os próprios seres sociais, autotransforma o próprio homem e a sua natureza humana. e como no interior do trabalho estão pela primeira vez presentes todas as determinações constitutivas da essência do ser social, ele se mostra como uma categoria originaria (ANTUNES, 1999. p. 145 - 146).

A reflexão e discussão aqui desenvolvida esta fundada nos textos de Marx. Por isso parte-se da premissa, conforme Marx, que não é possível pensar o homem sem pensar o trabalho. Pois o homem, "como criador de valor de uso, como trabalho útil, é indispensável à existência do homem quaisquer que sejam as formas de sociedade, é necessidade natural e eterna de efetivar o intercambio material entre o homem e a natureza e, portanto, de manter a vida humana" (MARX, 2008, p. 64)

Então, tendo o trabalho como categoria fundante, pode-se conceituá-lo como uma atividade histórica. Nas palavras de Marx:

Um processo de que participa o homem e a natureza, processo em que o ser humano, com sua própria ação, impulsiona, regula e controla seu intercambio natural com a natureza [...] Não se trata aqui de formas instintivas, animais, de trabalho. [...] Pressupomos o trabalho sob forma exclusivamente humana. uma aranha executa operações semelhantes às do tecelão, e a abelha supera mais de um arquiteto ao construir sua colméia. Mas o que distingue o pior arquiteto da melhor abelha é que ele figura na mente sua construção antes de transformá-la em realidade. No fim do processo de trabalho aparece um resultado que já existia antes idealmente na imaginação do trabalhador. Ele não transforma apenas o material sobre o qual opera; ele imprime ao material o projeto que tinha conscientemente em mira [...] os elementos componentes do processo de trabalho são: atividade adequada a um fim, isto é, o próprio trabalho [...] $\mathrm{O}$ processo de trabalho [...] é a atividade dirigida com fim de criar valores-de-uso, de apropriar os elementos naturais às necessidades humanas; é condição natural eterna da vida humana [...] sendo antes comum a todas as formas sociais (MARX, 2008, p. 211, 212, 218). 
Neste sentido passa-se a analisar na Pedagogia da Alternância o conceito de trabalho, pois, segundo Trindade,

é possível delimitar objetivamente os limites e possibilidades do sistema de alternância que surge como expressão da divisão do trabalho no contexto da revolução industrial. Pois, a análise de Marx mostra que a mesma lei que cria a alternância como espaço de educação que visa preparar o individuo para o trabalho fabril, acaba também universalizando a obrigatoriedade da escola. Temos, assim, a superação da oposição escola e não-escola - oposição que é historicamente contextual ao período pré-industrial - para o surgimento da oposição escola e escola, ou seja, continuamos a ter a escola para as classes possuidoras - para usar uma expressão de Manacorda - e agora também escola para as classes despossuidoras (TRINDADE, 2010. p. 76).

E Trindade ressalta ainda que a escola pública, laica e gratuita, "nasce capitalista, tendo como principio básico a alternância entre ensino e trabalho" (TRINDADE, 2010. p. 76). Por isso, discutir escola a partir da Revolução Industrial é discutir a escola capitalista. A ideia de alternância aparece neste processo como uma ideia essencialmente capitalista. Funcional ao capital neste momento e contexto histórico. Constitui-se historicamente "como categoria universal, isto é, uma categoria capitalista, por isso, essencialmente conservadora" (TRINDADE, 2010. p. 76).

Com efeito, buscou-se fazer paralelos de leituras e comparações com a prática e a teoria da Pedagogia da Alternância, para poder mostrar um recorte atual do nosso contexto histórico. Em outras palavras, mostrar se a proposta da Pedagogia da Alternância, no que diz respeito à categoria 'trabalho', se enquadra nos moldes capitalistas ou de superação deste. Visto que "o trabalho é entendido como um processo histórico, como atividade fundamental e necessária, seja para a manutenção ou para a transformação social" (TRINDADE, 2010. p. 67).

\section{3- Finalizações}

Tendo em vista de que se trata de uma pesquisa em fase de desenvolvimento, seria cedo apresentar conclusões, ou seja, isso seria precipitado demais no momento. A proposta foi apenas suscitar um debate nas questões que permeiam a categoria trabalho, em especial, como vem sendo apresentado o conceito trabalho na modalidade na proposta de educação da Pedagogia da Alternância.

Na era cientifica/tecnológica vemos a educação voltada para justamente as pessoas que trabalham ou irão trabalhar, em outras palavras, a educação visa formar/qualificar os indivíduos para se tornarem trabalhadores.

Então, nas diferentes épocas percebe-se um caráter fundamental do trabalho. $\mathrm{O}$ trabalho sempre esteve determinando a educação. Em outras palavras, a educação sempre se prontificou a prestar serviço ao trabalho.

Sabe-se que ao falar do trabalho como princípio educativo entrando-se em um arcabouço teórico polêmico. Pois, encontram-se leituras que fundamentam a PA como sendo a mais pura forma de salvação do filho do pequeno agricultor. Essa vertente crê que a PA está "des-alienando" o jovem que esta excluído da lógica de mercado competitivo do capitalismo. Ou seja, o jovem é induzido a se enquadrar nas práticas globais de consumo e comercialização dos produtos. Como se o alienado fosse o que está fora dos ideais capitalistas e liberais. E parece que até o presente momento é essa mentalidade que vem se 
desenvolvendo no modo de produção capitalista. E por outro lado, tem-se uma vertente que acredita que a PA é apenas mais uma proposta pedagógica da escola burguesa, pois desde o surgimento das CFRs o Estado se fez presente com sua "mão protetora".

Com efeito, percebe-se que a PA construiu e se apropriou de uma dinâmica própria para 'encaixar' os jovens que vivem no campo nos parâmetros de agricultura ditados pelo capital. Sem delongas, a PA quer transformar os filhos de pequenos agricultores em micro empresários rurais. Isto é, incorporar a pequena propriedade numa notável lógica de consumo e comércio típica dos grandes latifúndios. A PA transfere ao trabalho do jovem agricultor toda responsabilidade de desenvolvimento da pequena propriedade. Trabalho esse que se fosse desenvolvido em outro setor da sociedade seria taxado de 'trabalho infantil'.

Por outro lado, não de pode negar que a PA está inovando ao se preocupar com os camponeses, embora não tenha o interesse de revolucionar o modo de produção capitalista. Diz-se que está inovando, pois os camponeses sempre ficaram à margem nos modelos de educação. Acredita-se então que a educação para o cidadão que mora no campo tem a mesma relevância que a educação para o cidadão da cidade.

Não obstante, as possibilidades da PA são de promover uma educação para o trabalho no campo para o filho do agricultor. A PA tenta conciliar o tempo do estudo com o tempo de trabalho, no caso, agrícola, e isso é feito via alternância. A proposta é unir teoria e prática. Não resta dúvida que a PA tem como ideal o trabalho como princípio educativo. Mas, o modo de produção capitalista operante, não permite que de fato o trabalho seja colocado como princípio educativo. Para retomar um exemplo, atualmente o Estado tem assumido a responsabilidade dos pais na administração das CFRs. Assim, os limites da PA vão até o ponto onde há a convergência ou congruência entre interesses dos agricultores e do Estado. Pois desde a sua origem, a PA viu-se atrelada aos cuidados do Estado como mantenedor. E o Estado, como se sabe, é tipicamente burguês. Logo, a categoria trabalho defendida nas CFRs está mais para um princípio de alienação do que um princípio educativo.

Em se tratando de limites, a PA não pode ser vista como uma práxis revolucionária, mas como adequação do capital a uma classe que estava distante do mercado globalizado, por sua vez, capitalista. O seu limite está justamente em permitir que a revolução da burguesia chegue ao campo. Por isso o trabalho aparece mais uma vez como uma forma de alienar e não de conscientizar o trabalhador da sua real situação.

Até o momento procurou-se entender pelo viés da pesquisa, por onde caminha a proposta da Pedagogia da Alternância. Por isso, o desafio da pesquisa é justamente perscrutar essa intrigante proposta pedagógica que vem "dando certo" desde 1935 e perdura com uma dinâmica que lhe é peculiar. O que resta então é promover o debate acerca das reais possibilidades da Pedagogia da Alternância.

\section{Referências}

ANTUNES, Ricardo L. C.. Os sentidos do trabalho: ensaio sobre a afirmação e a negação do trabalho. São Paulo: Boitempo, 2003. 258 p.

BRAVERMAN, H. Trabalho e Capital Monopolista. A degradação do trabalho no século XX. 3.ed. Rio de Janeiro: Guanabara, 1987. 
CALVÓ, Pedro Puig. Introdução. In: Pedagogia da Alternância - alternância e desenvolvimento. Primeiro Seminário Internacional. Salvador: Dupligráfica Editora, 1999.

FORGEARD, G. Alternância e Desenvolvimento do Meio. In: Pedagogia da Alternância - alternância e desenvolvimento. Primeiro Seminário Internacional. Salvador: Dupligráfica Editora, 1999.

FRANCO, Maria Laura P. Barbosa. Possibilidades e limites do trabalho enquanto principio educativo. Cad. Pesquisa, São Paulo(68): 29-37, fevereiro 1989.

FRIGOTTO, Gaudêncio. O trabalho como princípio educativo no projeto de educação integral de trabalhadores- Excertos. 2005. Acesso em: www.escolanet.com.br/teleduc/.../9/.../Trabalho_principio_educ.doc, dia 10 de maio de 2011.

GIMONET, Jean-Claude. Nascimento e Desenvolvimento de um Movimento Educativo: As Casas Familiares Rurais de Educação e Orientação. In: Seminário Internacional Sobre Pedagogia da Alternância. Pedagogia da Alternância. Alternância e Desenvolvimento. Salvador, BA: SIMFR/VITAE/UNEFAB. 1999. p.39-48.

Praticar e compreender a pedagogia da alternância dos CEFFAs. Petópolis, RJ: Vozes, Paris: AIMFR - Associação Internacional dos Movimentos Familiares e de Formação Rural, 2007.

GRAMSCI, Antônio. Os intelectuais e a Organização da Cultura. 3.ed Trad. Carlos Nelson Coutinho. Rio de Janeiro: Civilização Brasileira, 1979.

LESSA, S. Mundo dos homens. Trabalho e ser social. São Paulo: Boitempo, 2002.

MARIRRODRIGA, Roberto Garcia; CALVÓ, Pedro Puig. Formación em alternancia y desarrollo local: el movimiento educativo de los CEFFA em el mundo. Argentina: Colección AIDEFA, 2007.

MARX, K. O capital. V. I, tomo 1. São Paulo: Abril Cultural, 1983.

MARX, K. O Capital. V. 1, Rio de Janeiro: Civilização Brasileira, 2008.

SAVIANI, Dermeval; LOMBARDI, José Claudinei; SANFELICE, José Luis (orgs). Capitalismo, trabalho e educação. Campinas: autores associados, 2002. (coleção educação contemporânea).

SAVIANI, Dermeval. O trabalho como principio educativo frente às novas tecnologias. 1998. Acesso em: http://forumeja.org.br/go/files/demerval\%20saviani.pdf, dia 10 de maio de 2011.

SILVA, L. H., As experiências de formação de jovens do campo - Alternância ou Alternâncias? Viçosa: UFV, 2003. 
SOARES, Solange Toldo; TRINDADE, Jussara das Graças. O trabalho como princípio educativo e sua dupla dimensão no capitalismo. 2007. Acesso em: http://www.slideshare.net/solangesoares/o-trabalho-como-princpio-educativo-e-sua-dupladimenso, dia 10 de maio de 2011.

SOUZA, João Valdir Alves de. Pedagogia da Alternância: uma alternativa consistente de escolarização rural? Disponível em: http://www.anped.org.br/

reunioes/31ra/1trabalho/GT14-4500--Int.pdf. acesso dia 22 de junho de 2011.

TANTON, Christian. Alternância e Parceria: Família e Meio Sócio-profissional. In: Seminário Internacional Sobre Pedagogia da Alternância. Pedagogia da Alternância. Alternância e Desenvolvimento. Salvador, BA: SIMFR/VITAE/UNEFAB. 1999.p.98-103.

TRINDADE, Glademir Alves. O trabalho e a pedagogia da alternância na casa familiar de Pato Branco - PR. 2010. 138 p. Dissertação (Mestrado em Educação) programa de Pós Graduação em Educação, Universidade Federal de Santa Catarina, Florianópolis, 2010.

TUMOLO, Paulo Sergio. O trabalho na forma social do capital e o trabalho como princípio educativo: uma articulação possível? Educ. Soc., Campinas, vol. 26, n. 90, p. 239-265, Jan./Abr. 2005

TUMOLO, Paulo Sergio; COAN, Marival. A categoria trabalho nos textos didáticos utilizados para o ensino de sociologia no ensino médio. 2008. Acesso dia 31 de maio de 201no site: http://www.uel.br/grupoestudo/gaes/pages/arquivos/GT3\%20Artigo\%20Heloiza\%20Vianna\%20Categoria\%20Trab alho.pdf.

TUMOLO, Paulo Sergio. Trabalho, estranhamento e exploração capitalista: dos Manuscritos econômico-filosóficos em direção ao Capital de Marx. In: ALVES, G.; BATISTA, R. L., GONZALEZ, J. L. C. (orgs.). Trabalho e educação: contradições do capitalismo global.1 ed. Maringá : Praxis, v.1, p. 146-161, 2006.

\footnotetext{
1 Graduado em filosofia pela FAE - Curitiba. Atualmente é aluno do Programa de Pós Graduação em Desenvolvimento Regional (PPGDR) - na UTFPR - Campus Pato Branco - PR.

${ }^{2}$ Professora Doutora em educação pela Unicamp. Atua como docente do Programa de Mestrado em Desenvolvimento Regional (UTFPR), com a disciplina Educação e Desenvolvimento Sustentável.
}

Recebido em julho de 2011

Aprovado em janeiro de 2012 